\title{
The role of mite pocket-like structures on Agama caudospinosa (Agamidae) infested by Pterygosoma livingstonei sp. $\mathrm{n}$. (Acari: Prostigmata: Pterygosomatidae)
}

\author{
Michel Bertrand ${ }^{1}$ and David Modrý $\dot{y}^{2,3}$ \\ ${ }^{1}$ UMR 5175 Département Ecologie des Arthropodes, Laboratoire de Zoogéographie, Université Montpellier III, Rte de Mende, \\ F-34199 Montpellier Cedex 5, France; \\ ${ }^{2}$ Department of Parasitology, University of Veterinary and Pharmaceutical Sciences, Palackého 1-3, 61242 Brno, Czech \\ Republic; \\ ${ }^{3}$ Institute of Parasitology, Academy of Sciences of the Czech Republic, Branišovská 31, 37005 České Budějovice, Czech \\ Republic
}

Key words: Pterygosomatidae, Agamidae, mite pockets, ectoparasites, host-parasite relationships

\begin{abstract}
Pterygosoma livingstonei sp. n. collected from the Kenyan lizard Agama caudospinosa Meek shows morphological affinities with other South African congener species parasitizing lizards of the genus Agama, especially with P. triangulare Lawrence, 1936, but it differs in having glabrous genua II and III. P. livingstonei shows affinities with the Lawrence's hispida species group in the characters of genital and peripheral setae. This new species was found concentrated in a nuchal "mite pocket-like structure", a behaviour previously unreported among species belonging to the genus Pterygosoma. Mite pockets (or acarodomatia, acarinaria) of lizards typically house damaging chigger mites, and are usually interpreted as the evolutionary host's response to limit damage caused by parasites. Because scale mites are permanent ectoparasites and less damaging than seasonally occurring larval trombiculids, the heavy infestation by $P$. livingstonei in the nuchal skin folds of its host is interpreted as a consequence of the best utilisation of an available protected site by these mites that spend their entire life cycle on their host and whose primitive body shape prevents them from seeking shelter beneath the scales of their lizard host.
\end{abstract}

The genera Pterygosoma Peters, 1849 (the true scale mites) and Geckobia Mégnin, 1878, parasites of the Agamidae and Gekkonidae, respectively, represent the well-known family Pterygosomatidae (Bertrand et al. 1995, 1999). The diversity of the Pterygosomatidae (number of species, endemic genera) in Austral Africa is great (Lawrence 1935, 1936, 1953) and attests to their endemicity in the Ethiopian Region. However, no pterygosomatid had been described from the Kenyan species Agama caudospinosa Meek, 1910 before we (D. Modrý) captured specimens heavily infested by a new species of Pterygosoma. These blood-feeding mites were concentrated in the shelter of skin folds located primarily at the base of the host's neck, in much the same way as larvae of chigger mites (Trombiculidae) are housed in the acarodomatia or mite pockets of gekkonid lizards, and from which also scale mites (identified as belonging to the genus Geckobia) were collected (Arnold 1986).

\section{MATERIALS AND METHODS}

More than 50 engorged mites were collected from one Agama caudospinosa, fixed in $70 \%$ ethanol, and later cleared in hot lactic acid and observed on temporary slides under a Leitz Dialux 20-EB microscope. The gnathosoma, mouthparts and legs of five specimens were dissected with pins in lactic acid. Whole mites or dissected structures were stained with Chlorazol Black B and mounted in lactic acid on concavity slides (depth $0.6 \mathrm{~mm}$ ) or in Hoyer's medium. Measurements were made on 10 individuals under the compound microscope, using the magnifying camera lucida.

\section{RESULTS}

Pterygosoma livingstonei $\mathrm{sp}$. $\mathrm{n}$.

Figs. 1-10

Description. Adult female. Medium-size species; body sub-triangular with very long chelicerae (Fig. 1). Body without chelicerae (from anterior margin of idiosoma to extremity of genital area) $520 \mu \mathrm{m}$ long (range 445-600 $\mu \mathrm{m}$ ); maximal width $600 \mu \mathrm{m}$ (485-750 $\mu \mathrm{m}$ ). At least five (often six) pairs of large and sharp setae (280-295 $\mu \mathrm{m}$ long) on posterior margin of the body. Dorsal setation confined to submedian, lateral and peripheral regions, median part of dorsum glabrous except for double pair of medium-size setae $(<75 \mu \mathrm{m}$ long) in posterior third. Lateral margins of body densely covered with serrate setae (Figs. 1, 2). Ventral side with only three pairs of long and sharp setae, most posterior pair near the genital area. Coxae in two distinct groups, directed forward (Fig. 8), with usual setation [3(=2+1)$2(=1+1)]$. Leg chaetotaxy (tibia)-(genu)-(femur)-(trochanter) typical of Pterygosoma group 2 (Jack 1964): (5$3-3-3)(3-0-0-1)(3-1-1-1)(1-1-1-1)$. Tarsi with usual 


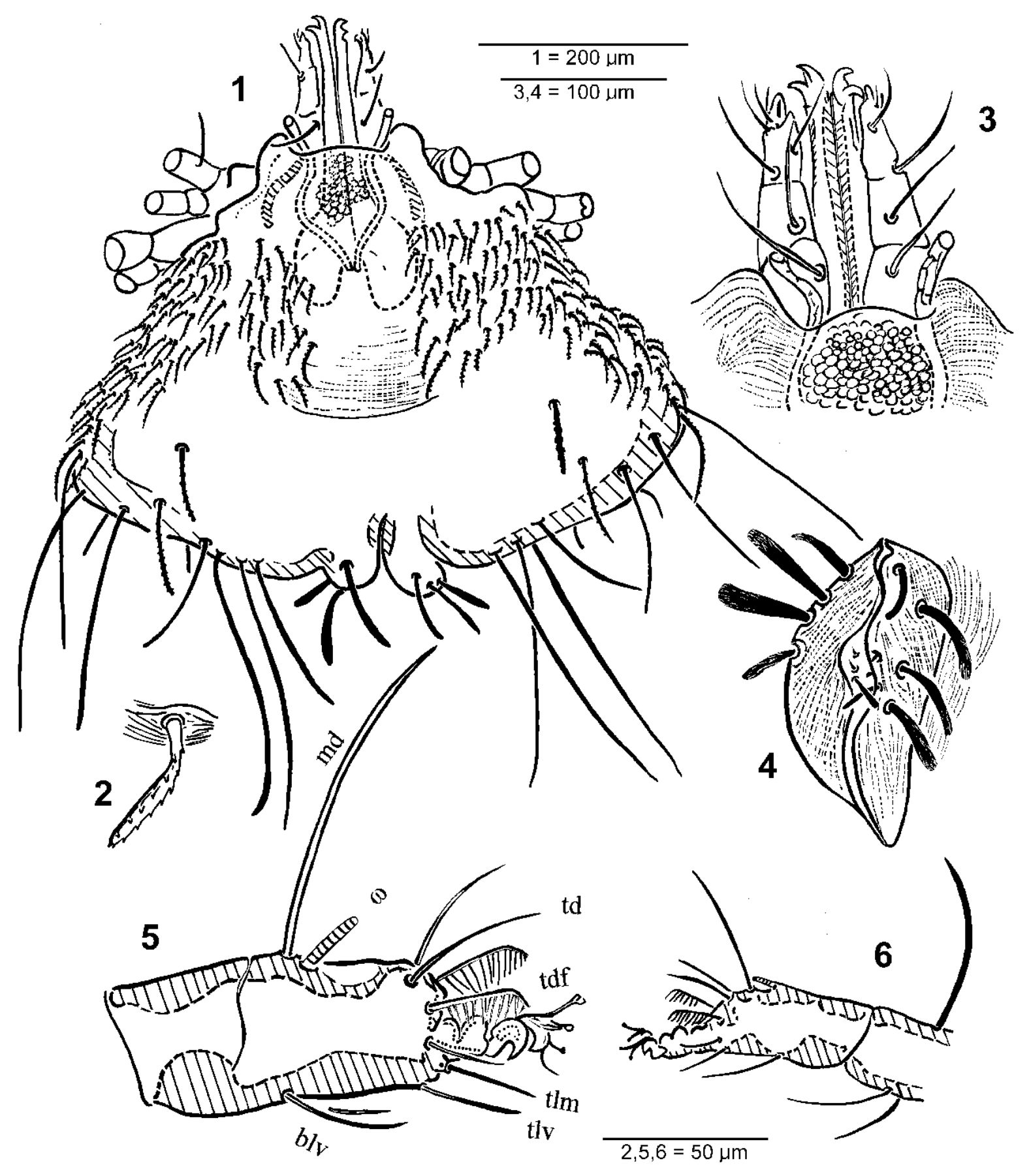

Figs. 1-6. Pterygosoma livingstonei sp. n., female. Fig. 1. Dorsal view. Fig. 2. Anterior seta. Fig. 3. Anterior part of idiosoma and gnathosoma, dorsal view. Fig. 4. Genital area. Fig. 5. Tarsus, first leg, lateral view ( $\omega$ - solenidion; md, td, tdf, tlm, tlv, blv notation of ordinary setae according to Jack (1964). Fig. 6. Tarsus, second leg, lateral view.

setae and solenidia (Figs. 5, 6), corresponding to Jack's species group A (Jack 1964).

Gnathosoma (Figs. 3, 7, 9, 10): Chelicerae very long $(200-250 \mu \mathrm{m})$ protrusible for $1 / 4$ of their length (Figs.
1, 3), extremity double hooked antiaxially, with bifid process in subterminal position (Fig. 10). Palp with the usual setae (1-1-3-6) and single subterminal claw-like seta surrounded by three longer simple setae (Figs. 


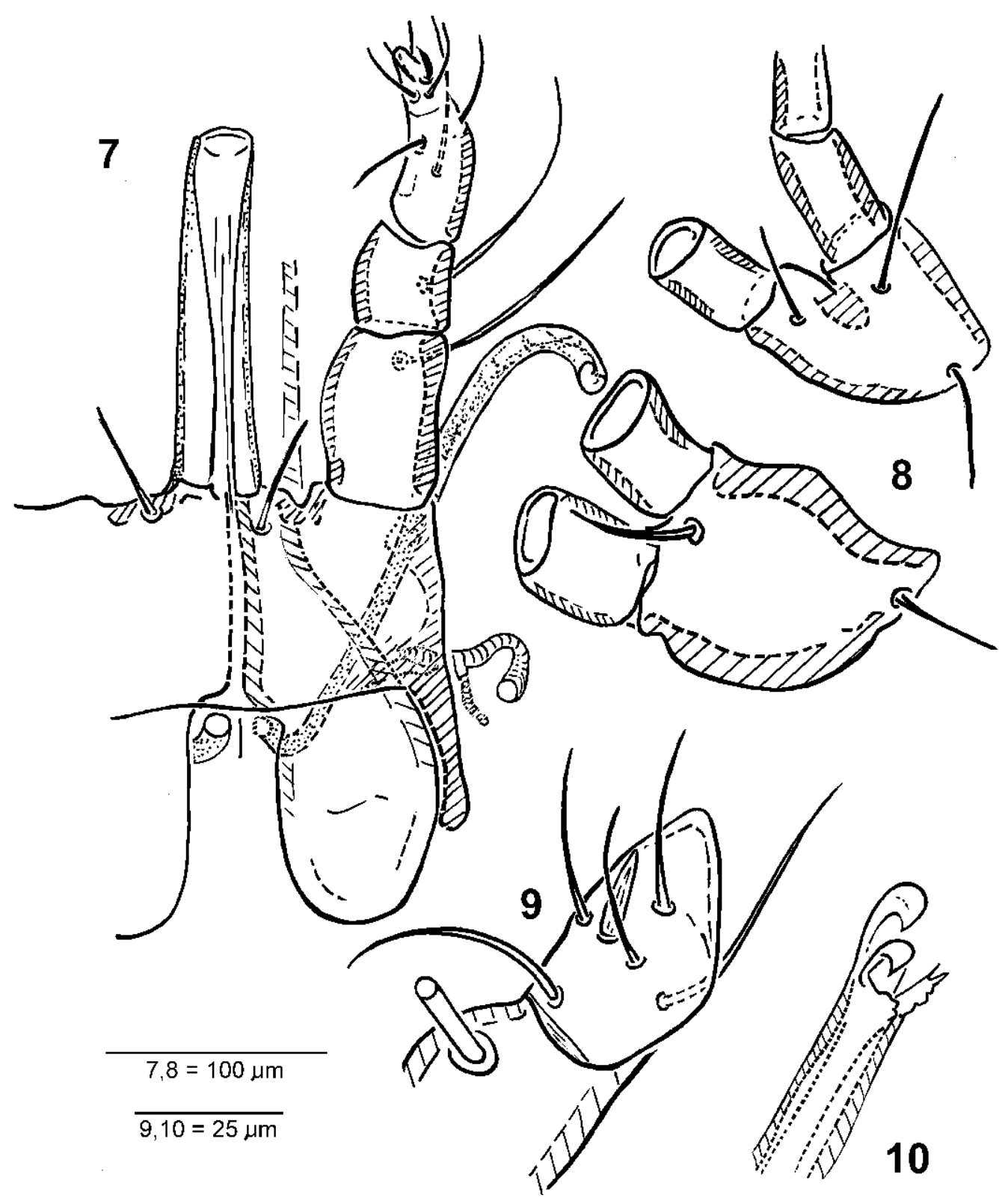

Figs. 7-10. Pterygosoma livingstonei sp. n., female. Fig. 7. Infracapitulum and palp, ventral view. Fig. 8. Coxal plates, ventral view. Fig. 9. Distal part of palp, ventral view. Fig. 10. Chelicera, distal part, ventral view.

3, 9). Gnathosoma surrounded by depression from which palpi, chelicerae and peritremes emerge; peritremes very long, stigmatal opening directed upward.

Genital area (Fig. 4): Genital lips each with four large and long setae each. Lips cover cavity with three pairs of setae of which the posterior is the largest.

Male: not collected.

T y p e h o s t : Agama caudospinosa Meek, 1910 (Sauria: Agamidae).

T y p e 1 o c a 1 i t y: Between Maralal and Baragoi (Central Kenya), approx. $1^{\circ} 22^{\prime}$ N, 37'E. 5/02/2001, Modrý coll.

$\mathrm{S}$ i t e of i n f e s t a t i o n : Skin fold at base of the neck

(Figs. 11, 12).
P r e v a l e n c e : $100 \%$ (5 lizards infested / 5 examined).

I n $\mathrm{ten} \mathrm{s}$ i t $\mathrm{y}$ : More than 30 mites in the anterohumeral skin fold of each host specimen examined. The maximum intensity 80 mites (40 in each skin fold, left and right side of lizard's body, respectively).

T y p e mate r i a 1 : Holotype and 9 paratypes in alcohol in the collection of Muséum national d'Histoire naturelle, Paris and 10 paratypes in the collection of the Institute of Parasitology, Academy of Sciences of the Czech Republic, České Budějovice (no. PaÚ 1991). All mites from one host specimen.

E t y m o 1 o g y: The species is named in honour of the Scottish explorer David Livingstone (1813-1873). 
Diagnosis. The leg chaetotaxy observed in $P$. livingstonei is similar to that of other species parasitic on Agama spp. from Southern Africa. This new species could be confused with $P$. triangulare Lawrence, 1936 in that they have a similar body shape and a similar modification of the distal tip of the chelicerae. These characters are also shared with $P$. tenuisetis Jack, 1962, $P$. melanum (Trägårdh, 1905) and $P$. agamae Peters, 1849 (Jack 1961, 1962a, b). The diagnostic characters of $P$. triangulare are the glabrous genua II and III, the presence of long setae on the posterior region of idiosoma, and the setation of palpi and tarsi I (Jack 1962a, b). P. livingstonei differs greatly from the other species of the Jack's group 2 (Jack 1964), and its general morphology and setation are at variance with the species of the inermis group (Jack 1962b). Considering Lawrence's (1936) species groups, P. livingstonei could be included in the hispida group, in that the anal hairs are not wider than long and are not racket shaped and the peripheral setae are long.

\section{DISCUSSION}

Pterygosoma livingstonei was found heavily concentrated in skin-fold acarodomatium-like structures similar to the iguanid "nuchal pockets" described by Arnold (1986). The mite pockets (Loveridge 1926) were mostly observed in arid countries on non-burrowing gekkonids (rather than on agamids) which were heavily infested by trombiculid larvae. The presence of $P$. livingstonei in a mite pocket-like structure was unexpected because such skin folds are rare on agamids (Arnold 1986) and because this type of sheltering behaviour was unknown in the genus Pterygosoma. Only mites of the genus Geckobia were previously reported housed in such structures on geckoes and it was an argument (Arnold 1986) for considering that the mite pockets were a host's co-evolutionary response to limit and contain damage caused by the parasite. The first interpretation might be that the presence of numerous $P$. livingstonei is the evidence of a coevolutionary host-parasite process. However, Bauer et al. (1990) argued that the origin and the maintenance of these skin folds cannot be explained solely in terms of mite pockets because skin folds of gekkonids provide shelter to both chiggers and Geckobia spp. Furthermore, "true" mite pockets are characterised by severe tissue changes (did the host inherit an anticipated defence?) which might be a direct consequence of the parasite's activity and the reaction to chigger feeding injuries (Bauer et al. 1990). However, because P. livingstonei is not greatly modified morphologically (cf. Bertrand 2002), the hypothesis of an opportunistic behaviour is plausible. This example illustrates the duality of the role played by acarodomatia, which either may provide an advantage to the host by limiting the areas attacked by damaging ectoparasites, or may provide an advantage to the parasites by providing shelter, especially if the parasites are morphologically unable to shelter under scales and thus find a limited protection from the grooming activity of the host. Two kinds of arguments strengthen the latter hypothesis: the morphology of a long-term parasite and the damages caused by a shortterm parasite.

Firstly, one can argue that the main problem facing an ectoparasite is successfully surviving and maintaining on its host; this problem is so universal and exacting that convergent characters supporting survival are widespread in parasitic mites and ticks spending their entire life cycle on the host (Hoogstraal and Kohls 1966, Hoogstraal et al. 1973, Klompen and Oliver 1993, Bertrand 2002). The less protected and more primitive pterygosomatid genera (e.g. Hirstiella Berlese, 1920 and Geckobiella Hirst, 1917) present a trombiculid body shape, longer than wide. The new species is considered as primitive because (1) its body shape is primitive (i.e. not greatly modified) (Hirst 1917, 1926, Bertrand 2002) and (2) it has long chelicerae ("slender mouthparts") characteristic of Pterygosoma spp. that attach to the host's body without protection (Lawrence 1936) whereas "short mouthparts" (regressive character?) were observed in the species adapted to living under scales. As the best fixing sites provide also the best shelter and protection from host's grooming (Bertrand 2002), the nuchal skin folds could favour the survival rate of non-protected ectoparasites such as $P$. livingstonei.

Secondly, both chigger mites and scale mites feed on blood of reptiles, but only the larval stage of trombiculids is parasitic. Trombiculid larvae are pre-adapted to parasitism ("opportunistic" group, spending less than $10 \%$ of life duration on the host) (Wohltmann 2000). Trombiculids are secondarily parasitic on reptiles and cause heavy seasonal damages (Shatrov 2000); this pressure may explain the strong adaptive host defence. On the other hand, the scale mites show different degrees of co-adaptation, are usually hosted by very few lizard species, and spend their entire life on the same individual. The pressure exerted by the Pterygosomatidae on host fitness seems too weak to explain strong host responses and is considered an unlikely justification for the maintenance of mite pockets.

The host's skin folds apparently ensure a good shelter for $P$. livingstonei, a long-term parasite. It is likely that the number of individual parasites is limited by the available space (only females were collected, which suggests that the infestation was not recent, while a full nuchal pocket housed only 40 mites). The paradox is that the shelter (=acarodomatia) both favours the otherwise poorly protected parasite and serves as a limiting factor to its increase. The concentrated mite infrapopulations that we observed were probably the result of many mites seeking shelter in the nuchal region rather than true mite pockets that reflected the host's response to pterygosomatid injury. The sheltering 

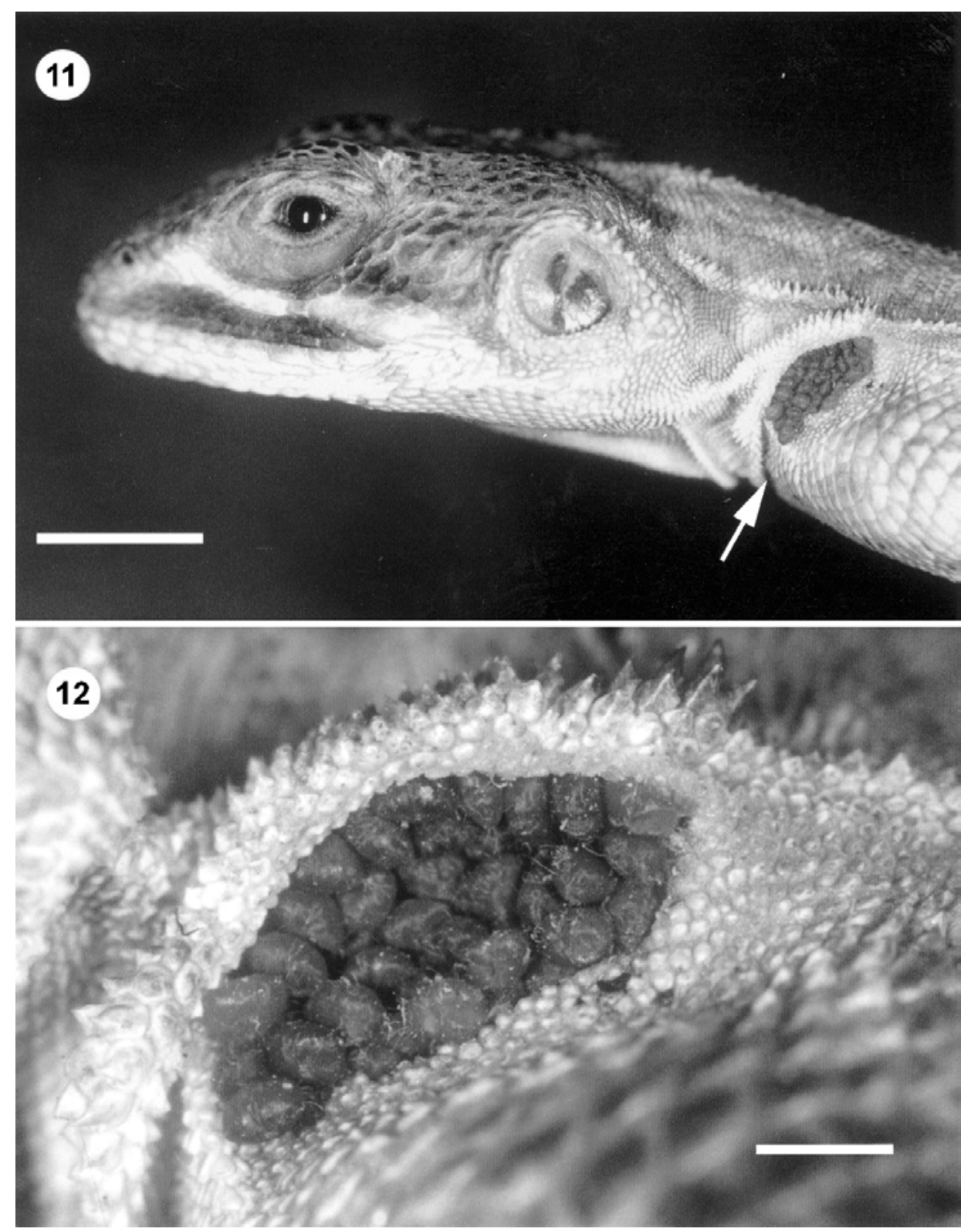

Fig. 11. Agama caudospinosa, lateral view of the head and neck (arrow - anterohumeral skin fold housing Pterygosoma livingstonei sp. n.). Fig. 12. Detail of Fig. 11. Scale bars: Fig. $11=10 \mathrm{~mm}$; Fig. $12=2 \mathrm{~mm}$.

behaviour of $P$. livingstonei was unexpected but is congruent with the general knowledge of the biology of the scale mites.

Acknowledgements. We are indebted to Asad Anwar (Nairobi) for organizing the transportation and logistics. Research trip in Kenya was sponsored by Masokombinát Písek a.s., and we are indebted to Dr. Ladislav Hájek for continuous generous support. Field studies of D.M. in Kenya were supported by the grants nos. 524/00P015 and 524/03/D104 from the Grant Agency of the Czech Republic and from the Institute of Parasitology, Academy of Sciences of the Czech Republic, research project AV0Z6022909. We are very grateful to Professor G.W. Krantz (Corvallis State University, USA) for the comments and improvement suggested to this article. 


\section{REFERENCES}

ARNOLD E.N. 1986: Mite pockets of lizards: a possible means of reducing damage by ectoparasites. Biol. J. Linn. Soc. 29: 1-21.

BAUER A.M., RUSSEL A.P., DOLLAHON N.R. 1990: Skin folds in the gekkonid genus Rhacodactylus: a natural test of the damage limitation hypothesis of mite-pocket function. Can. J. Zool. 68: 1196-1201.

BERTRAND M. 2002: Morphologic adaptations to parasitism in reptiles: Pterygosomatidae (Prostigmata: Raphignatina). In: F. Bernini, R. Nannelli, G. Nuzzacci and E. De Lillo (Eds.), Acarid Phylogeny and Evolution. Adaptations in Mites and Ticks. Kluwer Academic Publishers, Dordrecht, pp. 199-207.

BERTRAND M., PAPERNA I., FINKELMAN S. 1995: Etude préliminaire du genre Pterygosoma Peters, 1849 (Actinedida: Pterygosomidae): compléments à la description de Pterygosoma bibronii Jack, 1962 et notes sur les caractères évolutifs des Pterygosomidae. Acarologia 36: 133-143.

BERTRAND M., PAPERNA I., FINKELMAN S. 1999: Pterygosomatidae: descriptions et observations sur les genres Pterygosoma, Geckobia, Zonurobia et Hirstiella (Acari: Actinedida). Acarologia 40: 275-304.

HIRST A.S. 1917: On some new mites of the suborder Prostigmata living on lizards. Ann. Mag. Nat. Hist. 8: 136143.

HIRST A.S. 1926: On the parasitic mites of the suborder Prostigmata (Trombidoidea) found on lizards. J. Linn. Soc. Lond. 36: 173-200.

HOOGSTRAAL H., CLIFFORD C.M.N., KEIRANS J.M. 1973: Argas (Microargas) transversus (Ixodoidea: Argasidae) of Galapagos giant tortoises: description of the female and nymph. Ann. Entomol. Soc. Am. 66: 727-732.

Received 29 July 2003
HOOGSTRAAL H., KOHLS G.M. 1966: Argas (Microargas) transversus Banks (new subgenus) (Ixodoidea, Argasidae), a diminutive parasite of the giant tortoise: redescription of the holotype male and description of the larva. Ann. Entomol. Soc. Am. 59: 247-252.

JACK K.M. 1961: New species of Near Eastern agamid scalemites (Acarina, Pterygosomidae) with notes on the developmental stages of Geckobia hemidactyli Law., 1936. Parasitology 51: 241-256.

JACK K.M. 1962a: New species of Pterygosoma (Acari, Pterygosomidae). Proc. Zool. Soc. Lond. 138: 579-603.

JACK K.M. 1962b: Observations on the genus Pterygosoma. Parasitology 52: 261-295.

JACK K.M. 1964: Leg-chetotaxy with special reference to the Pterygosomidae (Acarina). Ann. Natal Mus. 16: 152-171.

KLOMPEN J.S.H., OLIVER J.H., Jr. 1993: Systematic relationships in the soft ticks (Acari: Ixodida: Argasidae). Syst. Entomol. 18: 313-331.

LAWRENCE R.F. 1935: The prostigmatic mites of South African lizards. Parasitology 27: 1-45.

LAWRENCE R.F. 1936: The prostigmatic mites of South African lizards. Parasitology 28: 1-39.

LAWRENCE R.F. 1953: Two new scales mites parasites on lizards. Proc. U.S. Natl. Mus. 103: 9-13.

LOVERIDGE A. 1926: A mite pocket in the Gecko Gymnodactylus lawderanus Stoliczka. Proc. Zool. Soc. Lond. 1925: 1431.

SHATROV A.B. 2000: On the origin of parasitism in trombiculid mites (Acariformes: Trombiculidae). Acarologia 41: 205-214.

WOHLTMANN A. 2000: The evolution of life histories in Parasitengona (Acari: Prostigmata). Acarologia 41: 145204.

Accepted 21 October 2003 